\title{
Exploring educational needs of multiple sclerosis care providers: Results of a care-provider survey
}

\author{
Aaron P. Turner, PhD $;^{1-2 *}$ Christine Martin, PhD $;^{3-4}$ Rhonda M. Williams, PhD; ${ }^{1-2}$ Kelly Goudreau, DSN, \\ RN; ${ }^{5}$ James D. Bowen, MD; ${ }^{1,6}$ Michael Hatzakis Jr, MD; ${ }^{1-2}$ Ruth H. Whitham, MD; ${ }^{5,7}$ Dennis N. Bourdette, \\ MD; ${ }^{5,7}$ Lynne Walker, RN, BSN, CRRN; ${ }^{1}$ Jodie K. Haselkorn, MD, MPH ${ }^{1-2}$ \\ ${ }^{1}$ Department of Veterans Affairs (VA) Puget Sound Health Care System, Seattle, WA; ${ }^{2}$ Department of Rehabilitation \\ Medicine, University of Washington, Seattle, WA; ${ }^{3}$ Baltimore VA Medical Center (VAMC), Baltimore, MD; ${ }^{4}$ Department \\ of Neurology, University of Maryland, College Park, MD; ${ }^{5}$ Portland VAMC, Portland, OR; ${ }^{6}$ Department of Neurology, \\ University of Washington, Seattle, WA; ${ }^{7}$ Department of Neurology, Oregon Health \& Science University, Portland, OR
}

\begin{abstract}
Our objective was to survey experienced multiple sclerosis (MS) care providers, determine their ongoing professional educational needs, and develop future education programs. We asked providers across a variety of disciplines to identify the areas in which clinical consultation and continuing medical education (CME) would most improve their ability to provide care to individuals with MS; their preferred education modalities; and their confidence in providing care related to disease-modifying agents (DMAs), fatigue, depression, spasticity, and bladder management. At a national meeting of MS professionals, 152 MS care providers completed a self-report survey that was designed for this cross-sectional cohort study. Areas of greatest interest for clinical consultation and CME were identical and included cognition, fatigue, DMA use, spasticity, pain, sex, diagnosis of MS, and depression. Participants expressed a preference for live and interactive CME modalities. Confidence in providing specific disease-related care sometimes differed between Veterans Health Administration (VHA) and non-VHA providers. The results indicate that clinical consultations and CME should be targeted to the topics of greatest interest identified by providers and delivered in a live or interactive modality whenever possible.
\end{abstract}

Key words: cognition, depression, disease-modifying agents, education, fatigue, multiple sclerosis, multiple sclerosis diagnosis, pain, sexual function, spasticity.

\section{INTRODUCTION}

We conducted this study to assess provider educational needs and to incorporate the identified needs into a national education program for multiple sclerosis (MS) care providers through the Department of Veterans Affairs (VA) Multiple Sclerosis Centers of Excellence (MSCoEs). The mission of the MSCoEs is to ensure that care for veterans with MS is offered at a consistently high level across the nation, through clinical consultation, research, information technology, and education. In particular, the educational mission includes dissemination of knowledge about evidence-based practices to Veterans Health Administration (VHA) providers from a broad

Abbreviations: $\mathrm{CD}=$ compact disc, $\mathrm{CME}=$ continuing medical education, DMA = disease-modifying agent, $\mathrm{MS}=$ multiple sclerosis, MSCoE = MS Center of Excellence, $\mathrm{SD}=$ standard deviation, VA $=$ Department of Veterans Affairs, VHA = Veterans Health Administration.

* Address all correspondence to Aaron P. Turner, PhD; Rehabilitation Care Service, S-117, VA Puget Sound Health Care System, 1660 S. Columbian Way, Seattle, WA 98108; 206-2776134; fax: 206-764-2263. Email: Aaron.Turner@med.va.gov DOI: 10.1682/JRRD.2004.11.0139 
variety of professional disciplines, geographic locations, and clinical settings.

Despite the widely recognized value of continuing medical education (CME) and the multitude of opportunities available for provider learning, a number of studies have indicated that simple participation in traditional CME activities is insufficient for promotion or support of changes in provider behavior [1-5]. In a comprehensive literature review that analyzed the efficacy of CME formats, Davis et al. found the most effective strategies for altering physician practices included reminders at the point of care, patient-mediated interventions, tailored outreach visits, and the presence of opinion leaders [2-3]. Didactic interventions that focus on knowledge delivery alone are not sufficient. Active learning, sequenced and longitudinal learning, and implementation promotion efforts in the work setting are more effective [3]. Finally, educational interventions that account for provider predisposition to change, assist with change, and reinforce change once it is made are recommended for sustaining new behaviors [6].

Different providers report different preferences for $\mathrm{CME}$ and also different goals and motivations. For example, physicians frequently express an interest in educational materials that are timely and easily accessible. They use resources such as the Internet to seek information about providing better care and answers to questions about specific patient problems [7]. Nurses, on the other hand, frequently express an interest in educational opportunities that are practice-based and problem-oriented [8]. Rehabilitation therapists also highly value hands-on learning, but they rely heavily on their peers for accessing new information regarding practice change [4]. Regardless of discipline, providers who practice selfdirected learning have expressed a need for guidance with their learning [9-10] and have listed such guidance as one of their more important educational needs [11].

The present needs assessment was part of a larger systematic effort for identification of the CME and clinical consultation topics that would be the most relevant to MS providers. In establishing this education plan, we considered several primary factors: (1) provider perceptions of areas of MS care that would be most improved with CME or professional consultation; (2) the importance of dissemination of existing best-practice guidelines, with special concentration on those areas in which providers reported least knowledge and least confidence with clinical guidelines; and (3) the importance of estab- lished adult education principles, which include the learning and change styles of providers and the practice context of the learners [9,12-13].

In summary, focused needs assessments are critical for ensuring that any educational intervention is relevant to the needs of the participants [14]. Questionnaires remain the cornerstone of such needs assessments, particularly among healthcare providers [12]. In this study, our ultimate goal was to establish a foundation from which we could plan effective education programs that would meet the needs of different providers and enhance clinical practice by promoting behavioral change that reflects evidence-based care.

\section{METHODS}

\section{Participants}

Participants were recruited from attendees of the 2003 Annual Conference of the Consortium of MS Centers in San Diego, California, as part of a larger effort that examined the educational and practice needs of individuals who provide healthcare services for people with MS. Of approximately 860 healthcare professionals who attended the conference, 152 completed surveys. Of these, 43 percent listed their primary employer as the VA. Individual demographic information was not collected (e.g., age, sex, race/ethnicity).

\section{Procedures}

The VA MSCoEs staff recruited MS professionals during a conference presentation and at the VA MSCoEs exhibition booth. Participants were asked to fill out a paper-and-pencil survey about their education and practice needs and provide their name and contact information if they wished to receive follow-up information. Individuals who completed the survey received a mug and a pen for their time. At a later date, we created a separate database of the survey data with all identifiers removed to summarize the data for publication. The University of Washington Human Subjects Review Board approved the use of this anonymous database.

\section{Measurements}

Survey questions for the current study were generated by a panel of MS experts that included four neurologists, two psychologists, three nurses, two physiatrists, and two adult education specialists. The survey questions were divided into four general sections. 


\section{Section I: Participant Description}

Section I contained nine questions about the professional background and practice setting of participants (e.g., where MS care is provided, occupation, number of years as MS care provider).

\section{Section II: Clinical Consultation}

In Section II, we listed 17 areas of clinical care typically required by individuals with MS (e.g., diseasemodifying agent [DMA] use, fatigue, depression) and asked participants to identify the top three areas in which receiving clinical consultation from a VA MSCoE professional would most improve their ability to care for individuals with MS.

\section{Section III: Continuing Medical Education and Preferred Modality}

Similarly, in Section III we asked participants to identify, from the same list of care topics presented for clinical consultation, the three topics of greatest interest for CME. Participants were also asked to indicate their preference for six different learning modalities (e.g., in-person conference, live educational broadcast, compact disc [CD]).

\section{Section IV: Clinical Assessment of Common Medical Concerns and Confidence in Adhering to Clinical Guidelines (Supplementary Section)}

We only asked physicians and registered nurse practitioners to answer a set of supplementary questions, which assessed typical clinical practice related to DMA use, bladder management, spasticity, and fatigue. These four topics were selected because widely recognized MS Council clinical practice guidelines have been published in each of these areas, and these guidelines allowed us an opportunity to examine clinicians' comfort levels in practicing evidence-based care. Specifically, we asked providers about their current clinical assessment practices for common medical concerns presented by persons with MS and also about their degree of confidence practicing in those clinical areas with best-practices guidelines.

\section{DATA ANALYSIS}

Analyses were limited to those who indicated that they provided direct patient care $(n=140)$. We used frequency counts and proportions to examine the topics of MS care of greatest interest to providers in terms of clini- cal consultation and CME. We used chi-square analyses to examine differences in proportions between VHA and non-VHA providers. We also examined preference for different CME modalities (live vs other and interactive vs other) using paired $t$-tests. Remaining analyses examined the frequency of assessment of MS medical concerns and confidence in the use of various therapeutic interventions (DMA, bladder therapy, spasticity therapy, and fatigue therapy). These later analyses were limited to physicians and nurse practitioners $(n=69)$, the providers most typically writing medication prescriptions and initiating consultations for services. Two types of analyses were conducted for each category of intervention. The first compared the same providers' ratings of confidence with different specific treatments (e.g., amantadine vs energy effectiveness strategies for fatigue). To reduce the total number of pairings, we limited the comparisons using paired $t$-tests to the following: the therapy with the highest mean confidence rating versus the average of all other therapies in that category and the therapy with the lowest mean confidence rating versus the average of all other therapies in that category. For the second type of analysis, we examined differences between VHA and nonVHA providers and their confidence in each treatment option using independent $t$-tests.

\section{RESULTS}

\section{Participants}

Most participants were physicians (19\% neurology, $5 \%$ physiatry, and $4 \%$ general internal medicine) and nurses (14\% advanced practice registered nurses and $25 \%$ registered nurses or licensed practical nurses with specific MS experience). The remaining 33 percent of participants reflected a broad variety of disciplines, including physical therapists (8\%), psychologists (5\%), social workers (4\%), occupational therapists (2\%), pharmacists (2\%), physician's assistants (1\%), speech and language pathologists (2\%), assistive technology specialists (1\%), and other disciplines (8\%). Professionals were employed in a variety of services, including neurology (47\%), rehabilitation medicine (19\%), spinal cord injury (11\%), primary care $(11 \%)$, or other services $(12 \%)$. Most, 79 percent, worked in outpatient settings, while 16 percent worked in acute inpatient settings and 5 percent worked in rehabilitation settings. Most had provided care to individuals with MS for many years, 4 percent 
reported less than $1 \mathrm{yr}$ of experience, 35 percent reported 1 to $5 \mathrm{yr}$ of experience, 24 percent reported 6 to $10 \mathrm{yr}$ of experience, 21 percent reported 11 to $20 \mathrm{yr}$ of experience, and 16 percent reported more than $20 \mathrm{yr}$ of experience.

\section{Clinical Consultation}

Participants were asked to identify areas in which clinical consultation with a VA MSCoE professional would most improve their ability to provide care to individuals with MS. Survey questions prompted care providers to choose up to three topics from a list of MS-related care topics. The eight topics selected most frequently are presented in Figure 1. Overall, care providers were most interested in receiving clinical consultation from a VA MSCoE professional in the following areas: cognition (31.0\%), fatigue (31.0\%), DMA use (26.8\%), spasticity (24.6\%), pain (23.9\%), sexual function (19.0\%), MS diagnosis (16.9\%), and depression (14.1\%). VHA providers showed greater interest in receiving consultations related to DMA use than non-VHA providers, 38.3 percent versus 17.5 percent, $\chi^{2}(1,140)=7.65, p<0.01$.

\section{Continuing Medical Education}

Participants were also asked to identify their areas of greatest interest for CME. Survey questions prompted care providers to choose up to three topics from the same list of care topics presented for clinical consultation. The eight topics selected most frequently are presented in Figure 2 and are identical to those identified for clinical consultation. Overall, care providers were most interested

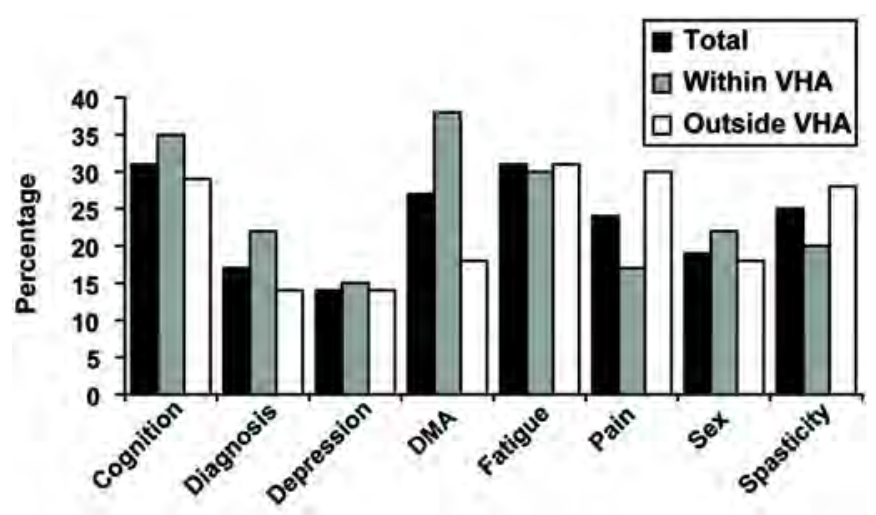

Figure 1.

Interest in clinical consultation for VHA vs non-VHA providers. Percentages represent proportion of MS providers interested in receiving consultation in that area of clinical care $(n=140)$. DMA = disease-modifying agent, VHA = Veterans Health Administration. in CME related to cognition (40.1\%), fatigue (32.4\%), DMA use (28.9\%), spasticity (24.6\%), pain (23.2\%), sexual function (19.7\%), MS diagnosis (20.4\%), and depression (14.8\%). VHA providers showed greater interest in receiving education regarding DMA use than non-VHA providers, 43.3 percent versus 17.5 percent, $\chi^{2}(1,140)=$ $11.21, p<0.001$.

\section{Differences in Interest in Clinical Consultation and Continuing Medical Education by Occupation}

The eight topics of greatest interest for clinical consultation and CME were also examined for different classes of providers. Because of limitations in the overall sample size, we created three groups: all physicians, all nursing professionals, and all other health professionals. Physicians showed greater interest in clinical consultation for DMA use than the other two professional classes grouped together, 45.2 percent versus 19.0 percent, $\chi^{2}(1,140)=10.39, p<0.001$. All other health professionals showed greater interest in clinical consultation for fatigue than the physicians and nurses grouped together, 50.0 percent versus 21.9 percent, $\chi^{2}(1,140)=11.50, p<0.001$ (Figure 3). Similarly, physicians showed greater interest in CME for DMA use than the other two professional classes grouped together, 45.2 percent versus 19.0 percent, $\chi^{2}(1,140)=10.39, p<0.001$. Also, all other health professionals showed greater interest in CME for fatigue than the physicians and nurses grouped together, 45.7 percent versus 26.0 percent, $\chi^{2}(1,140)=5.46, p<0.05$ (Figure 4).

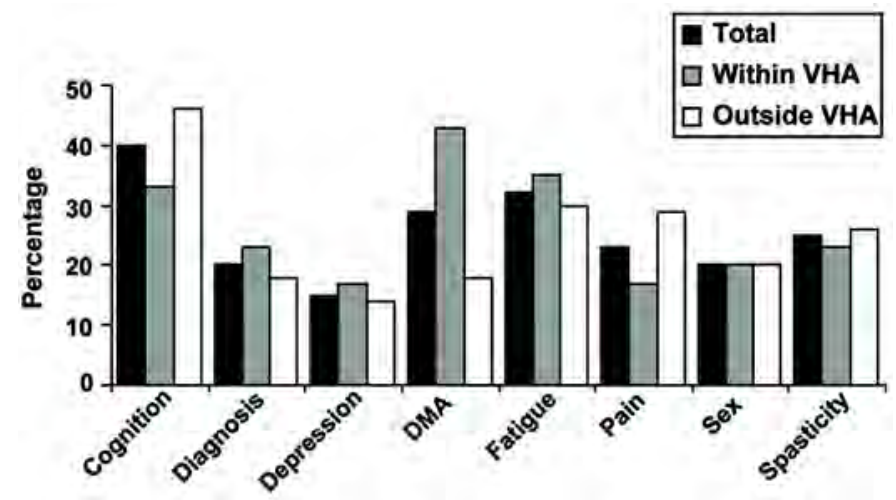

Figure 2.

Interest in continuing medical education for VHA vs non-VHA providers. Percentages represent proportion of MS providers interested in receiving continuing medical education in that area of clinical care $(n=140)$. DMA = disease-modifying agent, VHA = Veterans Health Administration. 


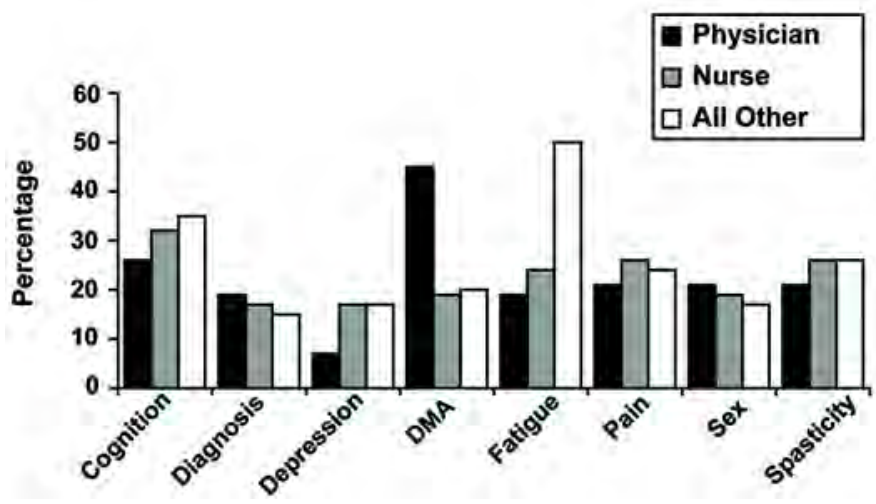

Figure 3.

Interest in clinical consultation: differences between disciplines. Percentages represent proportion of MS providers interested in receiving consultation in that area of clinical care $(n=140)$. DMA = disease-modifying agent.

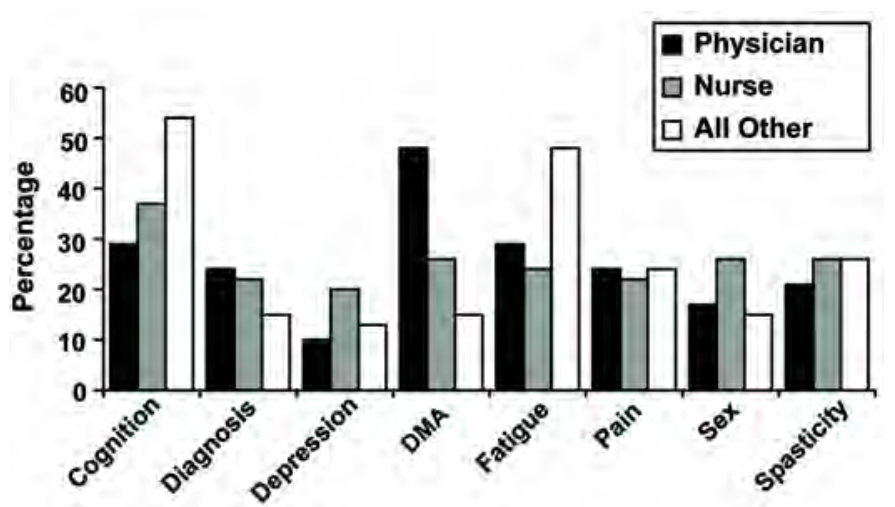

Figure 4.

Interest in continuing medical education: differences between disciplines. Percentages represent proportion of MS providers interested in receiving continuing medical education in that area of clinical care $(n=140)$. DMA = disease-modifying agent.

\section{Preferred Modality for Continuing Medical Education}

Interest in different modalities for continuing education was also examined in the survey. Participants were asked to rate their preference for various educational formats, with responses ranging from 1 "less helpful" to 3 "very helpful." Ratings are presented in Table 1. On average, participants gave their highest preference rating to a live conference, mean \pm standard deviation $(\mathrm{SD})=2.64 \pm$ 0.51 and their lowest rating to a taped broadcast, mean \pm $\mathrm{SD}=1.85 \pm 0.65$. Educational modalities were divided into two conceptual categories: live versus other modality (live conference and live broadcast vs all other) and inter-
Table 1.

Participants' mean \pm standard deviation (SD) self-reported ratings* ( 1 "less helpful" to 3 "very helpful") of preferred modalities for multiple sclerosis continuing medical education.

\begin{tabular}{lcc}
\hline \multicolumn{1}{c}{ Modality } & Mean \pm SD & $\begin{array}{c}\text { Independent } \\
\text { t-Test }^{\dagger}\end{array}$ \\
\hline Live Conference & $2.64 \pm 0.51$ & - \\
Live Broadcast & $2.10 \pm 0.65$ & - \\
Compact Disk & $2.19 \pm 0.70$ & - \\
Web-Based Module & $2.12 \pm 0.67$ & - \\
Taped Broadcast & $1.85 \pm 0.65$ & - \\
Mailed Module & $1.95 \pm 0.75$ & - \\
Live Modalities & $2.39 \pm 0.45$ & - \\
All Other Modalities & $2.01 \pm 0.48$ & - \\
Interactive Modalities & $2.25 \pm 0.37$ & - \\
Passive Modalities & $1.89 \pm 0.56$ & - \\
Live vs Other Modalities & - & 5.93 \\
Interactive vs Passive Modalities & - & 6.70 \\
${ }^{*} n$ varied from 107 to 135. & & \\
${ }^{\dagger} p<0.001$. & & \\
\hline \hline
\end{tabular}

active versus other modality (live conference, live broadcast, CD, and web-based module vs taped broadcast and mailed module). Participants showed a greater preference for live modalities, mean $\pm \mathrm{SD}=2.39 \pm 0.45$ versus all other modalities, mean $\pm \mathrm{SD}=2.01 \pm 0.48, t_{(106)}=5.93$, $p<0.001$ and for interactive modalities, mean $\pm \mathrm{SD}=$ $2.25 \pm 0.37$ versus passive modalities, mean $\pm \mathrm{SD}=$ $1.89 \pm 0.56, t_{(106)}=6.70, p<0.001$.

\section{Clinical Assessment of Common Medical Concerns}

Participants were asked to describe the frequency with which they assessed common MS-related medical concerns. Responses ranged from 1 "rarely" to 4 "systematically." Results are presented in Table 2. Participants most frequently assessed DMA use, mean $\pm \mathrm{SD}=$ $3.39 \pm 0.90$, although the difference from the average report of all other areas of assessment only trended toward significance, $t_{(57)}=1.95, p<0.06$. They least frequently assessed sexuality, mean $\pm \mathrm{SD}=2.89 \pm 1.00$, $t_{(57)}=-3.25, p<0.01$. Differences between VHA and non-VHA providers in assessment practices were also examined. VHA providers reported that they assessed fatigue less frequently than non-VHA providers, mean \pm $\mathrm{SD}=3.06 \pm 0.92$ versus $3.63 \pm 0.57, t_{(61)}=-2.85, p<$ 0.01 . VHA providers also reported that they assessed safety with less frequency, mean $\pm \mathrm{SD}=3.00 \pm 0.87$ versus $3.46 \pm 0.81, t_{(59)}=-2.10, p<0.05$. 
Table 2.

Participants' mean \pm standard deviation self-reported ratings" (1 “rarely" to 4 "frequently") of overall frequency of clinical assessment of common medical concerns for individuals with multiple sclerosis and difference in frequency rating by provider type (Veterans Health Administration [VHA] vs non-VHA).

\begin{tabular}{lccc}
\hline \multirow{2}{*}{ Medical Concern } & Overall Frequency Rating & \multicolumn{2}{c}{ Frequency Rating By Provider Type } \\
\cline { 3 - 4 } & & VHA & Non-VHA \\
\hline Cognition & $3.22 \pm 0.81$ & $3.11 \pm 0.82$ & $3.38 \pm 0.80$ \\
Fatigue & $3.27 \pm 0.88$ & $3.06 \pm 0.92$ & $3.63 \pm 0.57^{\dagger}$ \\
Depression & $3.23 \pm 0.79$ & $3.14 \pm 0.72$ & $3.41 \pm 0.84$ \\
Sexuality & $2.89 \pm 1.00^{\ddagger}$ & $2.80 \pm 0.96$ & $3.07 \pm 0.99$ \\
Safety & $3.18 \pm 0.88$ & $3.00 \pm 0.87$ & $3.46 \pm 0.81^{\S}$ \\
DMA Use & $3.39 \pm 0.90^{\uparrow}$ & $3.26 \pm 0.89$ & $3.60 \pm 0.91$ \\
\hline
\end{tabular}

${ }^{*} n$ varied from 59 to 64 .

${ }^{\dagger} p<0.01$.

${ }^{\ddagger}$ Rating of clinical area significantly differs from mean rating of remaining clinical areas at $p<0.05$.

$\S_{p}<0.05$.

१Rating of clinical area trends toward difference from mean rating of remaining clinical areas.

DMA = disease-modifying agent.

\section{Confidence in Disease-Modifying Agent Use}

Participants were asked to describe their confidence in the use of various DMA medications, with responses ranging from 1 "not confident" to 4 "very confident." Results are presented in Table 3. Participants were most confident in their use of Avonex ${ }^{\circledR}$, mean \pm SD $=3.20 \pm$ $1.19, t_{(54)}=2.57, p<0.01$ and least confident in their use of Novantrone ${ }^{\circledR}$, mean $\pm \mathrm{SD}=2.66 \pm 1.18, t_{(54)}=-4.43$, $p<0.001$. Confidence differences between VHA and non-VHA providers were also examined. VHA providers reported less confidence than their non-VHA counterparts in their use of Novantrone ${ }^{\circledR}$, mean \pm SD $=2.37 \pm$ 1.19 versus $3.08 \pm 1.04, t_{(53)}=-2.35, p<0.05$ and less confidence in their use of Rebif ${ }^{\circledR}$, mean \pm SD $=2.55 \pm$ 1.36 versus $3.56 \pm 0.89 t_{(56)}=-3.28, p<0.01$.

\section{Confidence in Bladder Therapies}

Similarly, participants were asked to describe their confidence in various bladder therapies with the same set of response options. Results are presented in Table 3. Participants were most confident in their use of Ditro$\operatorname{pan}^{\circledR}$, mean $\pm \mathrm{SD}=3.52 \pm 0.86, t_{(54)}=9.19, p<0.001$ and least confident in their use of Levsin ${ }^{\circledR}$, mean $\pm \mathrm{SD}=$ $1.97 \pm 1.12, t_{(54)}=-8.12, p<0.001$. No significant differences existed between VHA and non-VHA providers in confidence in bladder therapies.

\section{Confidence in Spasticity Therapies}

Participants were also asked to describe their confidence in various spasticity therapies with the same set of response options. Results are presented in Table 3.
Participants were most confident in their use of oral baclofen, mean $\pm \mathrm{SD}=3.66 \pm 0.76, t_{(52)}=10.71, p<$ 0.001 and least confident in their use of alcohol as a neurolytic blocker, mean $\pm \mathrm{SD}=1.54 \pm 0.98, t_{(52)}=-11.74$, $p<0.001$. VHA providers were more confident than their non-VHA counterparts in their use of Valium ${ }^{\circledR}$, mean \pm $\mathrm{SD}=3.44 \pm 0.89$ versus $2.90 \pm 1.18, t_{(61)}=2.04, p<$ 0.05 .

\section{Confidence in Fatigue Therapies}

Finally, participants were asked identical questions about their confidence in therapies for fatigue. Results are presented in Table 3. Participants were most confident in the use of amantadine, mean $\pm \mathrm{SD}=3.32 \pm 0.98, t_{(59)}=$ 4.25, $p<0.001$ and least confident in their use of Cylert ${ }^{\circledR}$, mean $\pm \mathrm{SD}=2.49 \pm 1.24, t_{(59)}=-4.27, p<0.001$. VHA providers were less confident than their non-VHA counterparts in their use of energy effectiveness strategies, mean $\pm \mathrm{SD}=2.51 \pm 1.00$ versus $3.41 \pm 0.91, t_{(66)}=$ $-3.83, p<0.001$; formal home exercise programs, mean \pm $\mathrm{SD}=2.69 \pm 0.86$ versus $3.17 \pm 1.04, t_{(66)}=-2.08, p<$ 0.05 ; Cylert $^{\circledR}$, mean $\pm \mathrm{SD}=2.16 \pm 1.09$ versus $3.00 \pm$ $1.27, t_{(62)}=-2.83, p<0.01$; and Provigil ${ }^{\circledR}$, mean $\pm \mathrm{SD}=$ $2.74 \pm 1.13$ versus $3.45 \pm 0.99, t_{(65)}=-2.69, p<0.01$.

\section{CONCLUSIONS}

In this study, our goal was to gather information about the needs, preferences, and current practices of healthcare professionals who treat individuals with MS for the 
Table 3.

Participants' mean \pm standard deviation self-reported ratings* (1 “not confident" to 4 "very confident”) of confidence in their use of multiple sclerosis therapies (disease modifying, bladder, spasticity, and fatigue therapies) and difference in confidence rating by provider type (Veterans Health Administration [VHA] vs non-VHA).

\begin{tabular}{|c|c|c|c|}
\hline \multirow{2}{*}{ Multiple Sclerosis Therapy } & \multirow{2}{*}{$\begin{array}{c}\text { Overall Confidence } \\
\text { Rating }\end{array}$} & \multicolumn{2}{|c|}{ Confidence Rating By Provider Type } \\
\hline & & VHA & Non-VHA \\
\hline \multicolumn{4}{|l|}{ Disease-Modifying Agent } \\
\hline Avonex $^{\circledR}$ (interferon $\beta$-1a) & $3.20 \pm 1.19^{\dagger}$ & $3.06 \pm 1.22$ & $3.44 \pm 1.09$ \\
\hline Betaseron ${ }^{\circledR}$ (interferon $\beta$-1b) & $3.15 \pm 1.22$ & $2.97 \pm 1.28$ & $3.44 \pm 1.05$ \\
\hline Copaxone $^{\circledR}$ (glatiramer acetate) & $3.17 \pm 1.19$ & $3.00 \pm 1.24$ & $3.46 \pm 1.03$ \\
\hline Novantrone ${ }^{\circledR}$ (mitoxantrone hydrochloride) & $2.66 \pm 1.18^{\dagger}$ & $2.37 \pm 1.19$ & $3.08 \pm 1.04^{\ddagger}$ \\
\hline Rebif ${ }^{\circledR}$ (interferon $\beta$-1a) & $2.98 \pm 1.28$ & $2.55 \pm 1.36$ & $3.56 \pm 0.89^{\S}$ \\
\hline \multicolumn{4}{|l|}{ Bladder } \\
\hline Postvoid Residual (catheterization) & $3.24 \pm 0.99$ & $3.25 \pm 0.95$ & $3.24 \pm 1.06$ \\
\hline Postvoid Residual (ultrasound) & $2.82 \pm 1.26$ & $2.82 \pm 1.26$ & $2.81 \pm 1.30$ \\
\hline Ditropan $^{\circledR}$ (oxybutynin) & $3.52 \pm 0.86^{\dagger}$ & $3.53 \pm 0.90$ & $3.52 \pm 0.85$ \\
\hline Detrol $^{\circledR}$ (tolterodine) & $3.27 \pm 1.11$ & $3.42 \pm 1.00$ & $3.17 \pm 1.17$ \\
\hline Tricyclic Antidepressant & $3.02 \pm 1.02$ & $3.06 \pm 1.03$ & $3.00 \pm 1.02$ \\
\hline Pro-Banthine ${ }^{\circledR}$ (propantheline) & $2.62 \pm 1.20$ & $2.76 \pm 1.20$ & $2.46 \pm 1.21$ \\
\hline Levsin ${ }^{\circledR}$ (hyoscyamine) & $1.97 \pm 1.12^{\dagger}$ & $1.97 \pm 1.11$ & $2.00 \pm 1.16$ \\
\hline \multicolumn{4}{|l|}{ Spasticity } \\
\hline Range of Motion & $3.62 \pm 0.68$ & $3.71 \pm 0.57$ & $3.52 \pm 0.80$ \\
\hline Baclofen (oral) & $3.66 \pm 0.76^{\dagger}$ & $3.82 \pm 0.39$ & $3.53 \pm 0.97$ \\
\hline Dantrium $^{\circledR}$ (dantrolene) & $2.65 \pm 1.19$ & $2.81 \pm 1.17$ & $2.54 \pm 1.20$ \\
\hline Valium $^{\circledR}$ (diazepam) & $3.17 \pm 1.06$ & $3.44 \pm 0.89$ & $2.90 \pm 1.18^{\ddagger}$ \\
\hline Zanaflex ${ }^{\circledR}$ (tizanidine) & $3.62 \pm 0.78$ & $3.69 \pm 0.59$ & $3.64 \pm 0.83$ \\
\hline Neurolytic Blocker (alcohol) & $1.54 \pm 0.98^{\dagger}$ & $1.48 \pm 0.91$ & $1.62 \pm 1.08$ \\
\hline Neurolytic Blocker (botulinum toxin) & $2.38 \pm 1.22$ & $2.27 \pm 1.26$ & $2.55 \pm 1.18$ \\
\hline Baclofen (intrathecal pump) & $2.59 \pm 1.19$ & $2.38 \pm 1.07$ & $2.90 \pm 1.26$ \\
\hline \multicolumn{4}{|l|}{ Fatigue } \\
\hline Energy Effectiveness & $2.87 \pm 1.07$ & $2.51 \pm 1.00$ & $3.41 \pm 0.91^{\Uparrow}$ \\
\hline Equipment Modification & $3.10 \pm 0.91$ & $2.97 \pm 0.96$ & $3.31 \pm 0.81$ \\
\hline Formal Home Exercise & $2.88 \pm 0.96$ & $2.69 \pm 0.86$ & $3.17 \pm 1.04^{\ddagger}$ \\
\hline Environmental Modifications & $2.91 \pm 0.98$ & $2.73 \pm 0.96$ & $3.21 \pm 0.90$ \\
\hline Amantadine & $3.32 \pm 0.98^{\dagger}$ & $3.18 \pm 1.01$ & $3.59 \pm 0.83$ \\
\hline Cylert $^{\circledR}$ (pemoline) & $2.49 \pm 1.24^{\dagger}$ & $2.16 \pm 1.09$ & $3.00 \pm 1.27^{\S}$ \\
\hline Ritalin ${ }^{\circledR}$ (methylphenidate) & $2.66 \pm 1.17$ & $2.50 \pm 1.08$ & $2.93 \pm 1.22$ \\
\hline Provigil $^{\circledR}$ (modafinil) & $3.01 \pm 1.14$ & $2.74 \pm 1.13$ & $3.45 \pm 0.99^{\S}$ \\
\hline \multicolumn{4}{|c|}{$\begin{array}{l}{ }^{*} n \text { varied from } 53 \text { to } 69 . \\
{ }^{\dagger} \text { Rating of clinical area significantly differs from mean rating of remaining clinical areas at } p<0.05 \text {. } \\
{ }^{\dagger} p<0.05 \text {. } \\
\$_{p}<<0.01 . \\
{ }^{\uparrow} p<0.001 .\end{array}$} \\
\hline
\end{tabular}

purpose of planning future education programs. Results suggest that providers were particularly interested in receiving clinical consultation and CME in the following areas: cognition, fatigue, DMA use, spasticity, pain, sexual function, MS diagnosis, and depression. VHA providers showed greater interest in clinical consultations related to DMA use than non-VHA providers. Overall, physicians were more interested than other health professionals in consultation/CME related to DMA use. Other health professionals (e.g., physical therapists, psychologists) were more interested in consultation/CME related to fatigue than physicians and nurses.

With regard to preferred education modality, provider preferences in the present sample reflect current 
theory as applicable to adult, self-directed learners. Providers expressed greatest interest in CME modalities that are both in-person and interactive. On average, participants gave their highest preference rating to a live conference and their lowest rating to a taped broadcast.

We also examined current practice in two areas, routine assessment of medical concerns and provider confidence with established clinical practice guidelines, to identify target areas for educational interventions. With regard to frequency of assessment, participants most frequently assessed DMA use, followed by fatigue, cognition, and depression. Providers were least likely to routinely assess sexuality. VHA providers reported that they assessed fatigue and safety less frequently than nonVHA providers; this result highlights these as areas for potential educational intervention. With regard to provider confidence in providing care that corresponds to established treatment guidelines, results were mixed. Levels of confidence varied markedly by medication across DMAs, bladder therapies, spasticity treatments, and fatigue treatments.

Overall, VHA and non-VHA providers were strikingly similar in their perceived educational needs and comfort with clinical practices across MS care domains. Several factors might help explain the limited instances in which differences were observed. The administration of Novantrone ${ }^{\circledR}$, for example, is sometimes difficult to coordinate at VA hospitals, which possibly explains why VHA providers reported a lower level of comfort with this treatment. In general, the VHA addresses the needs of a patient population that is predominantly male, older, and more disabled, with a different set of needs and problems [15]. Finally, the lower comfort level among VHA providers with treatments for fatigue such as energy effectiveness strategies and home exercise programs suggests that they may have less exposure to (and greater need for) rehabilitation-related CME.

The present needs assessment has several inherent methodological limitations. First, the sample only includes providers who already have sufficient expertise and interest in MS that they would be attending an international conference on MS. This is an important limitation to acknowledge because veterans with MS often receive at least some of their medical care from providers who are not MS specialists. Given the goal of providing accessible information to all providers who care for persons with MS, we need a broader sample. Second, the sample may have been biased by the setting (a live edu- cational conference) and recruitment limitations (participants were self-selected). Inherent limitations also exist in reliance on self-report data (e.g., social desirability). Third, the measures we used possess face validity but do not have established psychometric properties. Fourth, our response rate is relatively low. Fifth, in some instances, the overall number of statistical tests may have introduced some spurious results. Finally, provider confidence ratings may in some instances be affected by the nature of the clinical intervention itself, not simply by familiarity with it. For example, physicians may show a low level of confidence with the use of pemoline as an agent for fatigue not because they are unfamiliar with its use but because of its undesirable side effect profile.

Despite these limitations, the present study offers important information for the development of educational initiatives for MS care providers. Adult learning models emphasize the dynamic interaction of content providers, instructors, and informed learners, with the learners at the apex of that dynamic triad. From this perspective, assessment of provider needs is a critical first step.

\section{ACKNOWLEDGMENTS}

This material was based on work supported by the Department of Veterans Affairs (VA) Multiple Sclerosis Centers of Excellence, the VA Employee Education Service, and a VA Rehabilitation Research and Development Service Career Development Award (grant B3319VA) to Aaron P. Turner, PhD.

\section{REFERENCES}

1. Grimshaw JM, Russel IT. Effect of clinical guidelines on medical practice: A systematic review of rigorous evaluations. Lancet. 1993;342(8883):1317-22. [PMID: 7901634]

2. Davis DA, Thompson MA, Oxman AD, Haynes RB. Changing physician performance. A systematic review of the effect of continuing medical education strategies. JAMA. 1995;274(9):700-705. [PMID: 7650822]

3. Davis DA, O’Brien MA, Freemantle N, Wolf FM, Mazmanian P, Taylor-Vaisey A. Impact of formal continuing medical education: Do conferences, workshops, rounds, and other traditional continuing education activities change physician behavior or health care outcome? JAMA. 1999; 282(9):867-74. [PMID: 10478694]

4. Rappolt S, Tassone M. How rehabilitation therapists gather, evaluate, and implement new knowledge. J Contin Educ Health Prof. 2002;22(3):170-80. [PMID: 12227239] 
5. Umble KE, Cervero RM, Yang B, Atkinson WL. Effects of traditional classroom and distance continuing education: A theory-driven evaluation of a vaccine-preventable diseases course. Am J Public Health. 2000;90(8):1218-24. [PMID: 10937000$]$

6. Tu K, Davis DA. Can we alter physician behavior by educational methods? Lessons learned from studies of the management and follow-up of hypertension. J Contin Educ Health Prof. 2002;22(1):11-22. [PMID: 12004636]

7. Casebeer L, Bennett N, Kristofco R, Carillo A, Centor R. Physician Internet medical information seeking and on-line continuing education use patterns. J Contin Educ Health Prof. 2002;22(1):33-42. [PMID: 12004639]

8. Latter S, Speller V, Westwood G, Latchem S. Education for public health capacity in the nursing workforce: Findings from a review of education and practice issues. Nurse Educ Today. 2003;23(3):211-18. [PMID: 12672389]

9. Mann KV, Chaytor KM. Help! Is anyone listening? An assessment of learning needs of practicing physicians. Acad Med. 1992;67(10 Suppl):S4-6. [PMID: 1388550]

10. Snell L. The link between self-directed learning and continuing medical education. Alliance for CME Almanac. 2000;22(8):21-22.
11. Schon DA. Educating the reflective practitioner: Towards a new design for teaching and learning in the professions. San Francisco (CA): Jossey-Bass; 1987.

12. Mann KV. Not another survey! Using questionnaires effectively in needs assessment. J Contin Educ Health Prof. 1998;18(3):142-49.

13. Laxdal OE. Needs assessment in continuing medical education: A practical guide. J Med Educ. 1982;57(11):827-34. [PMID: 6752412]

14. Pololi L, Dennis K, Winn GM, Mitchell J. A needs assessment of medical school faculty: Caring for the caretakers. J Contin Educ Health Prof. 2003;23(1):21-29. [PMID: 12739256]

15. Vollmer TL, Hadjimichael O, Preiningerova J, Ni W, Buencosejo J. Disability and treatment patterns of multiple sclerosis patients in United States: A comparison of veterans and nonveterans. J Rehabil Res Dev. 2002;39(2):163-74. [PMID: 12051461]

Submitted for publication November 4, 2004. Accepted in revised form January 18, 2005. 